\title{
Intermolecular Interaction Energies in Molecular Crystals of 4-Formylcoumarin Derivatives
}

\author{
AHSAN ELAHI and RAJNI KANT* \\ Department of Physics \& Electronics, University of Jammu, Jammu Tawi -180 006, India \\ rkant.ju@gmail.com
}

Received 13 May 2015 / Accepted 4 June 2015

\begin{abstract}
Most of the crystallographic analysis that follows from structure determination involves interpretation of the molecular geometry and a working knowledge of a variety of intra- and intermolecular interactions based purely on geometrical considerations (distance and angle cut off criteria). The missing link is to explore the energetics associated with these interactions, particularly intermolecular ones, which provide a platform for the molecules to associate with each other. In this regard, PIXEL calculations have been performed on a series of six molecules of 4-formylcoumarin derivatives. PIXEL calculations suggest the presence of different structural motifs that play significant role in the stabilization of the structure. Analysis of these motifs shows that bifurcated C-H...O and $\pi \ldots \pi$ stacking are the major contributors towards the stabilization of the structure. However, it is found that molecular pairs interacting via dimeric $\mathrm{C}=\mathrm{O} \ldots \mathrm{C}=\mathrm{O}$ interaction also make significant contribution of almost $-5 \mathrm{kcal} \mathrm{mol}^{-1}$. In addition to these motifs, the role of weak $\mathrm{C}-\mathrm{H} \ldots \mathrm{X}(\mathrm{F}, \mathrm{Cl}$ or $\mathrm{Br}$ ) has also been explored in the stabilization of molecular packing.
\end{abstract}

Keywords: Coumarin, PIXEL, Hydrogen bonding, Intermolecular interactions, Lattice energy

\section{Introduction}

Coumarins form an important group of naturally occurring compounds possessing a $2 \mathrm{H}$-1-benzopyran-2-one nucleus. The derivatives of coumarins usually occur as secondary metabolites present in seeds, roots and leaves of many plant species ${ }^{1}$. Coumarins derivatives are widely recognized in the pharmaceutical industry for their broad structural diversity as well as their wide range of pharmacological activities. Coumarins have been reported to possess numerous medicinal activities which include enzymatic inhibition, anticoagulant, anticonvulsant, antioxidant and anti-inflammatory activities etc. ${ }^{2,3}$. The diversity of biological effects of these molecules is due to the nature of different ring substitutents ${ }^{4}$.

Hydrogen bonds play a vital role in crystal engineering because of their three peculiar features i.e. strength, directionality and flexibility ${ }^{5}$. Strong hydrogen bonds such as O-H...O and $\mathrm{N}-\mathrm{H} . . \mathrm{O}$ are well documented ${ }^{6,7}$, but weak interactions such as $\mathrm{C}-\mathrm{H} \ldots \mathrm{O}, \mathrm{C}-\mathrm{H} \ldots \pi$, $\mathrm{C}-\mathrm{H} . . . \mathrm{X}$ (X-halogen atom) and $\mathrm{C}-\mathrm{H}$... $\mathrm{N}$ have also attracted considerable interest because of their frequent occurrence in organic crystal structures ${ }^{8-12}$. The recent focus is to investigate 
the role of weak intermolecular interactions and its influence on crystal packing. In addition to the description of the crystal packing in terms of the presence of different intermolecular interactions, based purely on the concept of geometry (distance-angle criteria), it is also very important to analyze the intermolecular interaction energies of different non-covalent interactions in the solid state in order to obtain more detailed insight into the crystalpacking $^{13-16}$.

In this regard, a series of six molecules of 4-formylcoumarin derivatives have been taken into account and calculated theoretically their lattice energies by using PIXEL approach. The chemical name, molecular code, chemical structure for each structure is presented in Table 1. The X-ray crystallographic structures of these molecules are already reported ${ }^{17}$ and their precise crystallographic description is presented in Table 2. We have performed energy calculations by obtaining CIF files of these molecules from CCDC. All the molecular pairs involved in the crystal packing were extracted from crystal packing after PIXEL calculation and the nature and energies associated with the intermolecular interactions associated with these molecular pairs were analyzed to explore the role of these interactions in the stabilization of the crystal lattice. A representative illustration of the coumarin moiety indicating the atomic numbering scheme used for the present work is shown in Figure 1.

Table 1. Chemical name, coding scheme and chemical structure of the compounds

\begin{tabular}{lll}
\hline Code & Chemical Name & 4-formylcoumarin \\
6-2 & 7-Chloro-4-formylcoumarin \\
7-Bromo-4-formylcoumarin & 7-Fluoro-4-formylcoumarin \\
M-5 & 6-Fluoro-4-formylcoumarin \\
7-6 &
\end{tabular}


Table 2. Precise crystallographic details of 4-formylcoumarin derivatives

\begin{tabular}{ccccccc}
\hline Data & $\mathbf{M}-\mathbf{1}$ & $\mathbf{M}-\mathbf{2}$ & $\mathbf{M}-\mathbf{3}$ & $\mathbf{M}-\mathbf{4}$ & $\mathbf{M}-\mathbf{5}$ & $\mathbf{M}-6$ \\
\hline $\begin{array}{c}\text { Formula } \\
\text { Mol. }\end{array}$ & $\mathrm{C}_{10} \mathrm{H}_{6} \mathrm{O}_{3}$ & $\mathrm{C}_{10} \mathrm{H}_{5} \mathrm{ClO}_{3}$ & $\mathrm{C}_{10} \mathrm{H}_{5} \mathrm{ClO}_{3}$ & $\mathrm{C}_{10} \mathrm{H}_{5} \mathrm{BrO}_{3}$ & $\mathrm{C}_{10} \mathrm{H}_{5} \mathrm{FC}$ & $\mathrm{C}_{10} \mathrm{H}_{5} \mathrm{~F}$ \\
Weight & 174.15 & 208.59 & 208.59 & 253.05 & 192.14 & 192.14 \\
\hline $\begin{array}{c}\text { Crystal } \\
\text { system }\end{array}$ & Monoclinic & Monoclinic & Monoclinic & Monoclinic & Monoclinic & Triclinic \\
\hline $\begin{array}{c}\text { Space } \\
\text { group }\end{array}$ & $\mathrm{P} 21 / \mathrm{c}$ & $\mathrm{P} 21 / \mathrm{n}$ & $\mathrm{P} 21 / \mathrm{n}$ & $\mathrm{P} 21 / \mathrm{c}$ & $\mathrm{P} 21 / \mathrm{n}$ & $\mathrm{P} \overline{1}$ \\
\hline $\mathrm{a}(\AA)$ & $3.824(1)$ & $7.0980(1)$ & $7.984(2)$ & $8.122(1)$ & $6.115(1)$ & $5.746(1)$ \\
$\mathrm{b}(\AA)$ & $9.108(1)$ & $8.5800(1)$ & $5.939(1)$ & $10.216(1)$ & $8.082(1)$ & $8.552(1)$ \\
$\mathrm{c}(\AA)$ & $22.252(2)$ & $14.328(2)$ & $18.452(2)$ & $10.709(2)$ & $16.330(5)$ & $9.212(2)$ \\
$\alpha\left(^{\circ}\right)$ & 90 & 90 & 90 & 90 & 90 & $113.792(3)$ \\
$\beta\left({ }^{\circ}\right)$ & $91.263(5)$ & $97.913(5)$ & $101.333(5)$ & $92.753(5)$ & $94.23(1)$ & $102.163(3)$ \\
$\gamma\left({ }^{\circ}\right)$ & 90 & 90 & 90 & 90 & 90 & $93.126(3)$ \\
$\mathrm{Z}$ & 4 & 4 & 4 & 4 & 4 & 2 \\
$\mathrm{R}$ & 0.0592 & 0.0281 & 0.0582 & 0.0417 & 0.0597 & 0.0585 \\
\hline
\end{tabular}<smiles>O=c1ccc2ccccc2o1</smiles>

Figure 1. Coumarin moiety indicating the atomic numbering Scheme used

\section{Theoretical calculations}

PIXELC module embedded in Couloumb-London-Pauli (CLP) computer program package (version 13.2.2012) has been used for performing interaction energy calculations in the undertaken structures ${ }^{18-20}$. Intermolecular energy is calculated as a numerical integral over a large number of electron density pixels, obtained from a standard molecular orbital calculation (20K pixels for a typical medium-size organic molecule). One of the advantages of this method is that it allows the total energy to be partitioned into coulombic, polarization, dispersion and repulsion contributions, which enable us to have better understanding of the nature and role of these interactions in the stabilization of the crystal packing ${ }^{21-23}$. The total lattice energy partitioned into such components for the compounds M1-M6 is presented in Table 3. All the stabilizing molecular pairs involved in crystal packing were selected from the mlc output file (generated after PIXEL energy calculations) and were analyzed with their interaction energies. The symmetry operator and centroid-centroid distance along with coulombic, polarization, dispersion, repulsion and total interaction energies between the molecular pairs are presented in Table 4. Mercury software ${ }^{24}$ is employed to generate these molecular motifs and packing diagrams. The geometrical restrictions placed on the intermolecular $H$-bonds present in the selected molecular pairs are the sum of the van der Waals radii $+0.4 \AA$ and the directionality is greater than $110^{\circ}$. 
Table 3. Lattice energy from CLP (in $\mathrm{kcal} \mathrm{mol}^{-1}$ )

\begin{tabular}{cccccc}
\hline Molecule & $\mathrm{E}_{\text {Coul }}$ & $\mathrm{E}_{\text {Pol }}$ & $\mathrm{E}_{\text {Disp }}$ & $\mathrm{E}_{\text {Rep }}$ & $\mathrm{E}_{\text {Tot }}$ \\
\hline M-1 & -9.53 & -2.91 & -22.9 & 13.95 & -21.41 \\
M-2 & -10.58 & -3.44 & -26.45 & 16.87 & -23.63 \\
M-3 & -11.49 & -3.72 & -26.74 & 17.3 & -24.66 \\
M-4 & -13.4 & -3.58 & -26.67 & 20.07 & -23.58 \\
M-5 & -10.37 & -3.01 & -21.84 & 14.19 & -21.05 \\
M-6 & -12.33 & -3.53 & -22.46 & 16.53 & -21.77 \\
\hline
\end{tabular}

Table 4. PIXEL interaction energies (I.E.) $\left(\mathrm{kcal} \mathrm{mol}^{-1}\right)$ between molecular pairs related by a symmetry operation and the associated intermolecular interactions in the crystal

\begin{tabular}{|c|c|c|c|c|c|c|c|c|}
\hline Motif & $\begin{array}{c}\text { Centroid } \\
\text { Distance } \\
(\AA)\end{array}$ & $\mathrm{E}_{\text {Coul }}$ & $\mathrm{E}_{\mathrm{Pol}}$ & $\mathrm{E}_{\text {Disp }}$ & $\mathrm{E}_{\mathrm{Rep}}$ & $\mathrm{E}_{\text {Tot }}$ & Symmetry & $\begin{array}{l}\text { Important } \\
\text { interactions }\end{array}$ \\
\hline \multicolumn{9}{|c|}{ M-1 } \\
\hline 1 & 7.414 & -5.57 & -1.48 & -3.20 & 3.37 & -6.86 & $\begin{array}{c}1-x,-1 / 2+y \\
1 / 2-z\end{array}$ & $\begin{array}{l}\mathrm{C} 3-\mathrm{H} 3 \ldots \mathrm{O} 1, \\
\mathrm{C} 3-\mathrm{H} 3 \ldots \mathrm{O} 2, \\
\mathrm{C} 9-\mathrm{H} 9 \ldots \mathrm{O} 2, \\
\mathrm{C} 8-\mathrm{H} 8 \ldots \mathrm{O} 2\end{array}$ \\
\hline 2 & 3.824 & -0.88 & -0.97 & -9.39 & 6.57 & -4.71 & $-1+\mathrm{x}, \mathrm{y}, \mathrm{z}$ & $\begin{array}{c}\text { Molecular } \\
\text { stacking, } \\
\mathrm{C}=\mathrm{O} \ldots \mathrm{C}=\mathrm{O}\end{array}$ \\
\hline 3 & 6.585 & -1.38 & -0.62 & -2.94 & 1.17 & -3.80 & $\begin{array}{c}2-\mathrm{x},- \\
1 / 2+\mathrm{y}, 1 / 2-\mathrm{z}\end{array}$ & $\begin{array}{l}\mathrm{C} 8-\mathrm{H} 8 \ldots \mathrm{O} 2, \\
\mathrm{C} 3-\mathrm{H} 3 \ldots \mathrm{O} 1, \\
\mathrm{C} 9-\mathrm{H} 9 \ldots \mathrm{O} 2\end{array}$ \\
\hline 4 & 7.961 & -2.15 & -0.57 & -2.60 & 1.82 & -3.51 & $3-x, 1-y, 1-z$ & C6-H6...O3 \\
\hline 5 & 6.900 & -0.64 & -0.14 & -2.58 & 0.62 & -1.46 & $2-x, 1-y, 1-z$ & $\mathrm{C}=\mathrm{O} \ldots \mathrm{C}\left(\mathrm{sp}^{2}\right)$ \\
\hline 6 & 9.108 & -0.21 & -0.34 & -1.48 & 0.83 & -1.19 & $x,-1+y, z$ & C7-H7...O3 \\
\hline 7 & 9.935 & -0.50 & -0.33 & -1.94 & 1.00 & -0.76 & $3-x, 2-y, 1-z$ & $\begin{array}{c}\mathrm{C}\left(\mathrm{sp}^{2}\right)-\mathrm{H} \ldots \mathrm{H}- \\
\mathrm{C}\left(\mathrm{sp}^{2}\right)\end{array}$ \\
\hline \multicolumn{9}{|c|}{ M-2 } \\
\hline 1 & 3.488 & -1.72 & -1.55 & -12.09 & 8.46 & -6.93 & $1-x,-y, 1-z$ & $\begin{array}{c}\text { Molecular } \\
\text { stacking }\end{array}$ \\
\hline 2 & 3.661 & -1.17 & -1.15 & -11.35 & 7.17 & -6.50 & $-\mathrm{x},-\mathrm{y}, 1-\mathrm{z}$ & $\begin{array}{c}\text { Molecular } \\
\text { stacking }\end{array}$ \\
\hline 3 & 8.088 & -4.80 & -1.29 & -3.70 & 3.51 & -6.26 & $\begin{array}{c}1 / 2-x,- \\
1 / 2+y, 1.5-z\end{array}$ & $\begin{array}{l}\mathrm{C} 3-\mathrm{H} 3 \ldots \mathrm{O} 1, \\
\mathrm{C} 3-\mathrm{H} 3 \ldots \mathrm{O} 2, \\
\mathrm{C} 9-\mathrm{H} 9 \ldots \mathrm{O} 2, \\
\mathrm{C} 8-\mathrm{H} 8 \ldots \mathrm{O} 2\end{array}$ \\
\hline 4 & 8.820 & -1.69 & -0.53 & -2.15 & 1.43 & -2.94 & $\begin{array}{c}-1 / 2+\mathrm{x},-1 / 2- \\
\mathrm{y},-1 / 2+\mathrm{z}\end{array}$ & $\mathrm{C} 7-\mathrm{H} 7 \ldots \mathrm{O} 2$ \\
\hline 5 & 9.000 & -2.10 & -0.38 & -1.57 & 1.24 & -2.82 & $1-x, 1-y, 1-z$ & C9-H9...O3 \\
\hline 6 & 8.544 & -0.47 & -0.41 & -2.1 & 0.84 & -2.15 & $\begin{array}{c}1 / 2+\mathrm{x}, 1 / 2- \\
\mathrm{y}, 1 / 2+\mathrm{z}\end{array}$ & C9-H9...Cl1 \\
\hline 7 & 8.617 & -0.86 & -0.31 & -2.67 & 1.81 & -2.03 & $\begin{array}{c}1 / 2- \\
\mathrm{x}, 1 / 2+\mathrm{y}, 1 / 2-\mathrm{z}\end{array}$ & $\begin{array}{c}\mathrm{C}\left(\mathrm{sp}^{2}\right)- \\
\mathrm{Cl} \ldots \mathrm{O}=\mathrm{C}\end{array}$ \\
\hline
\end{tabular}




\begin{tabular}{|c|c|c|c|c|c|c|c|c|}
\hline 8 & 8.580 & -0.41 & -0.31 & -1.69 & 0.83 & -1.57 & $x,-1+y, z$ & $\begin{array}{l}\mathrm{C} 7-\mathrm{H} 7 \ldots \mathrm{O} 3 \\
\mathrm{C} 8-\mathrm{H} 8 \ldots \mathrm{O} 3\end{array}$ \\
\hline \multicolumn{9}{|c|}{ M-3 } \\
\hline 1 & 3.725 & -1.84 & -1.17 & -10.49 & 6.05 & -7.45 & $1-x,-y, 1-z$ & $\begin{array}{l}\text { Molecular } \\
\text { stacking }\end{array}$ \\
\hline 2 & 4.327 & -1.41 & -0.86 & -8.84 & 4.94 & -6.16 & $2-x,-y, 1-z$ & $\begin{array}{c}\text { Molecular } \\
\text { stacking }\end{array}$ \\
\hline 3 & 6.594 & -3.51 & -1.43 & -4.42 & 4.04 & -5.32 & $1-x,-1-y, 1-z$ & $\begin{array}{l}\mathrm{C} 8-\mathrm{H} 8 \ldots \mathrm{O} 2 \\
\mathrm{C} 8-\mathrm{H} 8 \ldots \mathrm{O} 1\end{array}$ \\
\hline 4 & 5.939 & -2.34 & -0.52 & -4.18 & 2.08 & -4.97 & $x,-1+y, z$ & $\mathrm{C}=\mathrm{O} \ldots \mathrm{C}=\mathrm{O}$ \\
\hline 5 & 7.724 & -2.84 & -0.78 & -3.48 & 2.7 & -4.39 & $2-x, 1-y, 1-z$ & $\begin{array}{l}\mathrm{C} 5-\mathrm{H} 5 \ldots \mathrm{O} 3, \\
\mathrm{C} 6-\mathrm{H} 6 \ldots \mathrm{O} 3\end{array}$ \\
\hline 6 & 9.444 & -2.92 & -1.00 & -2.17 & 2.72 & -3.37 & $\begin{array}{c}1.5-\mathrm{x},- \\
1 / 2+\mathrm{y}, 1.5-\mathrm{z} \\
\end{array}$ & $\mathrm{C} 3-\mathrm{H} 3 \ldots \mathrm{O} 2$ \\
\hline 7 & 9.923 & -1.17 & -0.64 & -2.17 & 2.41 & -1.57 & $\begin{array}{c}-1 / 2+x, 1 / 2- \\
y,-1 / 2+z\end{array}$ & C9-H9...Cl1 \\
\hline 8 & 9.947 & -0.02 & -0.16 & -1.79 & 0.76 & -1.24 & $\begin{array}{c}1.5- \\
x, 1 / 2+y, 1 / 2-z\end{array}$ & C6-H6...Cl1 \\
\hline \multicolumn{9}{|c|}{ M-4 } \\
\hline 1 & 8.418 & -6.14 & -1.77 & -3.73 & 5.06 & -6.59 & $\begin{array}{c}-\mathrm{x},-1 / 2+\mathrm{y},- \\
1 / 2-\mathrm{z}\end{array}$ & $\begin{array}{l}\mathrm{C} 3-\mathrm{H} 3 \ldots \mathrm{O} 1, \\
\text { C9-H9...O2, } \\
\text { C8-H8...O2 }\end{array}$ \\
\hline 2 & 4.049 & -1.53 & -1.19 & -10.54 & 7.03 & -6.21 & $-\mathrm{x},-\mathrm{y},-\mathrm{z}$ & Stacking \\
\hline 3 & 4.086 & -2.01 & -0.67 & -9.03 & 5.62 & -6.07 & $1-x,-y,-z$ & Stacking \\
\hline 4 & 7.509 & -2.27 & -0.74 & -4.42 & 2.72 & -4.71 & $\begin{array}{c}\mathrm{x}, 1 / 2-\mathrm{y},- \\
1 / 2+\mathrm{z}\end{array}$ & $\mathrm{C}=\mathrm{O} \ldots \mathrm{C}=\mathrm{O}$ \\
\hline 5 & 8.217 & -1.82 & -0.54 & -3.15 & 2.46 & -3.06 & $\begin{array}{c}1- \\
\mathrm{x}, 1 / 2+\mathrm{y}, 1 / 2-\mathrm{z} \\
\end{array}$ & $\begin{array}{l}\mathrm{C} 6-\mathrm{H} 6 \ldots \mathrm{O} 3 \\
\mathrm{C} 5-\mathrm{H} 5 \ldots \mathrm{Br} 1 \\
\end{array}$ \\
\hline 6 & 10.216 & -1.62 & -0.38 & -2.03 & 2.98 & -1.07 & $x,-1+y, z$ & $\begin{array}{c}\mathrm{C}\left(\mathrm{sp}^{2}\right)- \\
\mathrm{Br} 1 \ldots \mathrm{O} 3 \\
\end{array}$ \\
\hline \multicolumn{9}{|c|}{ M-5 } \\
\hline 1 & 7.517 & -4.87 & -1.31 & -2.82 & 2.92 & -6.09 & $-1-x,-y, 1-z$ & C8-H8...O2 \\
\hline 2 & 6.115 & -2.7 & -0.57 & -3.68 & 1.96 & -4.97 & $-1+\mathrm{x}, \mathrm{y}, \mathrm{z}$ & $\mathrm{C}=\mathrm{O} \ldots \mathrm{C}=\mathrm{O}$ \\
\hline 3 & 4.109 & -0.16 & -1.07 & -8.91 & 6.26 & -3.89 & $-\mathrm{x},-\mathrm{y}, 1-\mathrm{z}$ & Stacking \\
\hline 4 & 5.224 & -0.88 & -0.35 & -5.68 & 3.08 & -3.82 & $-\mathrm{x}, 1-\mathrm{y}, 1-\mathrm{z}$ & Stacking \\
\hline 5 & 7.575 & -2.25 & -0.69 & -1.79 & 1.91 & -2.82 & $\begin{array}{c}-1 / 2-\mathrm{x},- \\
1 / 2+\mathrm{y}, 1 / 2-\mathrm{z}\end{array}$ & $\mathrm{C}=\mathrm{O} \ldots \mathrm{C}=\mathrm{O}$ \\
\hline 6 & 8.529 & -1.33 & -0.41 & -1.96 & 0.95 & -2.74 & $\begin{array}{c}1 / 2+x, 1 / 2- \\
y, 1 / 2+z\end{array}$ & C3-H3...F1 \\
\hline 7 & 7.907 & -1.26 & -0.38 & -1.65 & 1.15 & -2.15 & $\begin{array}{c}1 / 2-x,- \\
1 / 2+y, 1 / 2-z\end{array}$ & C3-H3... 3 \\
\hline 8 & 7.903 & -0.38 & -0.24 & -2.22 & 1.34 & -1.50 & $1-\mathrm{x}, 1-\mathrm{y}, 1-\mathrm{z}$ & C5-H5...F1 \\
\hline \multicolumn{9}{|c|}{ M-6 } \\
\hline 1 & 8.490 & -8.15 & -2.17 & -3.8 & 5.76 & -8.36 & $-\mathrm{x},-\mathrm{y},-\mathrm{z}$ & $\mathrm{C} 3-\mathrm{H} 3 \ldots \mathrm{O} 2$ \\
\hline 2 & 6.899 & -5.99 & -1.84 & -3.44 & 4.95 & -6.33 & $-\mathrm{x}, 1-\mathrm{y}, 1-\mathrm{z}$ & C8-H8...O2 \\
\hline 3 & 4.092 & -1.26 & -0.86 & -8.15 & 5.13 & -5.13 & $1-x, 1-y, 1-z$ & $\begin{array}{l}\text { Molecular } \\
\text { stacking }\end{array}$ \\
\hline
\end{tabular}




\begin{tabular}{|c|c|c|c|c|c|c|c|c|}
\hline 4 & 5.746 & -2.25 & -0.67 & -4.44 & 2.48 & -4.89 & $-1+x, y, z$ & $\mathrm{C}=\mathrm{O} \ldots \mathrm{C}=\mathrm{O}$ \\
\hline 5 & 4.519 & -1.31 & -0.86 & -7.91 & 5.54 & -4.52 & $1-x,-y, 1-z$ & $\begin{array}{l}\text { Molecular } \\
\text { stacking }\end{array}$ \\
\hline 6 & 7.809 & -3.23 & -1.00 & -3.35 & 3.51 & -4.04 & $2-x,-y, 1-z$ & C5-H5_..O3 \\
\hline 7 & 9.344 & -1.17 & -0.33 & -1.88 & 1.26 & -2.13 & $2-x, 1-y, 2-z$ & C6-H6...F1 \\
\hline 8 & 9.718 & -0.07 & -0.17 & -1.00 & -0.72 & -0.55 & $\mathrm{x}, 1+\mathrm{y}, 1+\mathrm{z}$ & C9-H9...F1 \\
\hline
\end{tabular}

\section{Results and Discussion}

\section{4-Formylcoumarin (M-1)}

Molecular pairs (1-7) providing significant contribution towards the stabilization along with their interaction energies are shown in Figure 2. The molecular pair with maximum energy stabilization (motif 1) shows the presence of bifurcated $\mathrm{C}-\mathrm{H}$... O hydrogen bonds in which donor atom $\mathrm{H} 3$ (interacting with $\mathrm{O} 1$ and $\mathrm{O} 2$ ) and acceptor atom $\mathrm{O} 2$ (interacting with $\mathrm{H} 3$ and $\mathrm{H} 9)$ are bifurcated. Along with these interactions, this pair also shows C8-H8...O2 interaction and hence results in a total interaction energy of $-6.86 \mathrm{kcal} \mathrm{mol}^{-1}$ with $55 \%$ contribution from coulombic component. This molecular pair along with pairs 4 (dimeric C6-H6...O3, I.E. $\left.=-3.51 \mathrm{kcal} \mathrm{mol}^{-1}\right), 6\left(\mathrm{C} 7-\mathrm{H} 7 \ldots \mathrm{O} 3, \mathrm{I} . \mathrm{E}=-1.19 \mathrm{kcalmol}^{-1}\right)$ and $7($ dimeric $\mathrm{C}-\mathrm{H}$...H-C, I.E. $\left.=-0.76 \mathrm{kcal} \mathrm{mol}^{-1}\right)$ participate in the formation of a two dimensional molecular sheet in the bc plane as shown in Figure 3a. The packing in the crystal also involves the stacking of the molecules along a-axis via motif 2 , contributing $-4.71 \mathrm{kcal} \mathrm{mol}^{-1}$ (80\% dispersion contribution) towards stabilization. Adjacent stacks are then interlinked via motif $6(\mathrm{C} 7-\mathrm{H} 7 \ldots \mathrm{O} 3)$ forming layers in the ab plane (Figure $3 \mathrm{~b})$.

\section{6-Chloro-4-formylcoumarin (M-2)}

The molecular pairs (1-8) extracted from the crystal packing along with their respective interaction energies are shown in Figure 4. The maximum stabilization to the structure comes from molecular stacking. Molecules are stacked along the crystallographic a-axis via motif 1 and 2 , both having similar interaction energies (-6.93 and $-6.5 \mathrm{kcal} \mathrm{mol}^{-1}$ ) with major dispersion component (Table 4). The stacked dimers are then connected via dimeric C9H9...O3 (motif 5, I.E $=-2.82 \mathrm{kcal} \mathrm{mol}^{-1}$ ) and bifurcated acceptor C-H...O (H7 and H8 with O3, motif 8, I.E. $=-1.57 \mathrm{kcal} \mathrm{mol}^{-1}$ ) intermolecular interactions as shown in Figure 5a. The packing in the crystal also displays the formation of molecular chains via motif 3 (-6.26 kcal $\left.\mathrm{mol}^{-1}\right)$ and $8\left(-1.57 \mathrm{kcal} \mathrm{mol}^{-1}\right)$. The chains thus formed are interconnected with $\mathrm{C}\left(\mathrm{sp}^{2}\right)$ $\mathrm{Cl1} \ldots \mathrm{O} 3=\mathrm{C}$ (motif 7) dipolar interaction (Figure 5b) having a contribution of $-2.03 \mathrm{kcal} \mathrm{mol}^{-1}$ towards stabilization, the dispersion component (70\%) imparting the maximum stabilization.
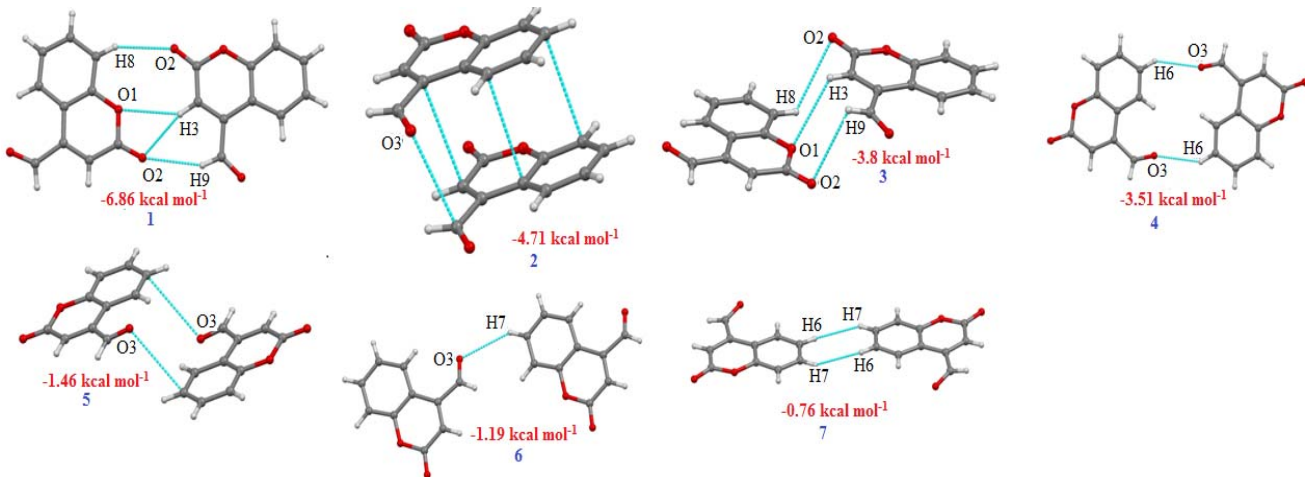

Figure 2. Molecular pairs (1-7) along with their interaction energies in C-1 


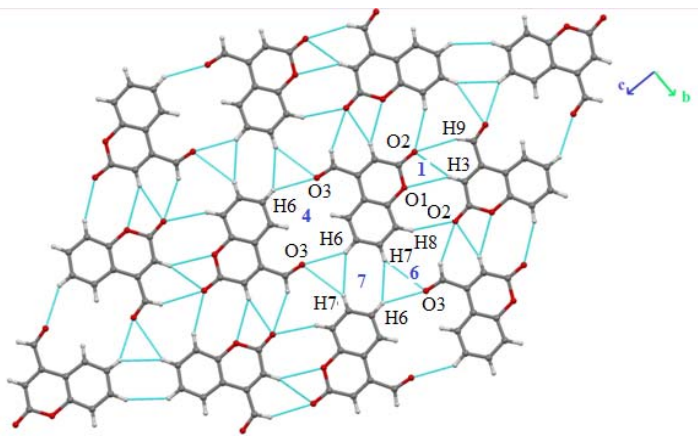

(a)

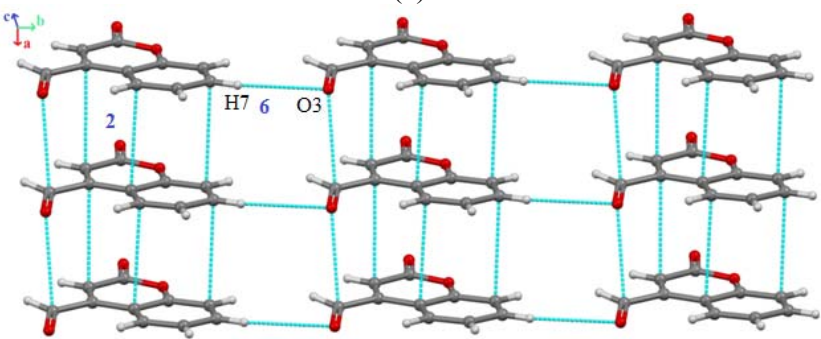

(b)

Figure 3. Packing of the molecules in C-1 showing (a) formation of sheets in the bc plane (b) stacking of the molecular down the ab plane
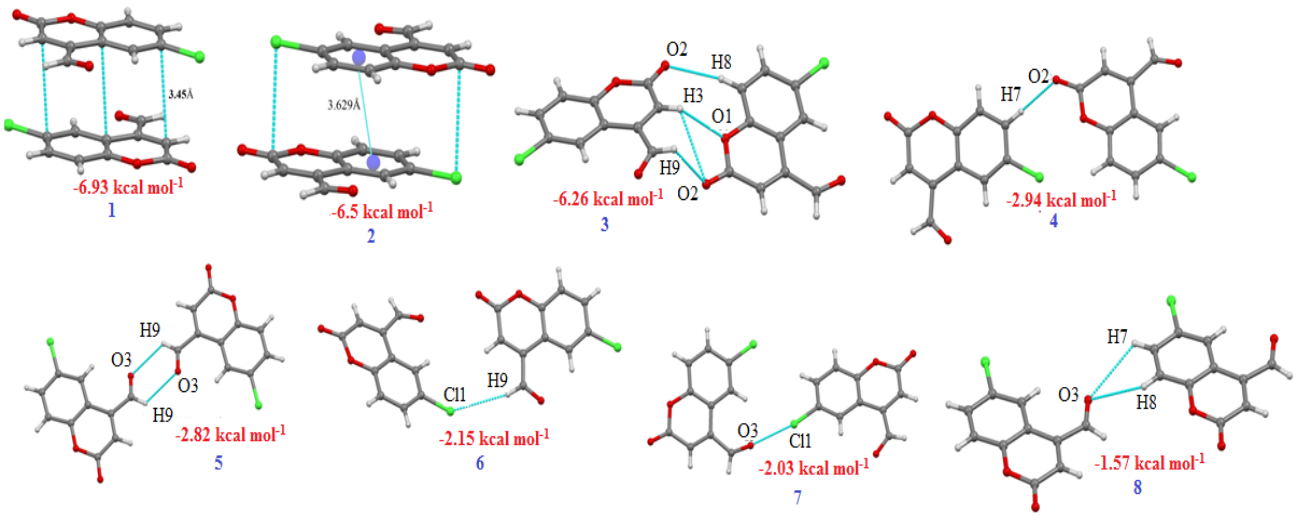

Figure 4. Molecular pairs (1-8) along with their interaction energies in C-2

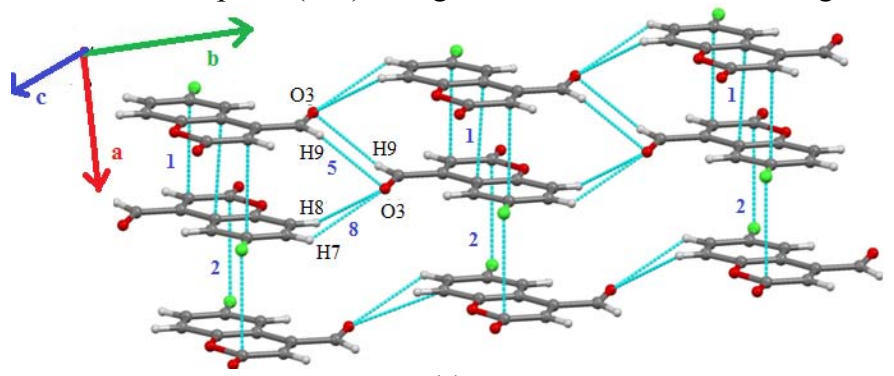

(a) 


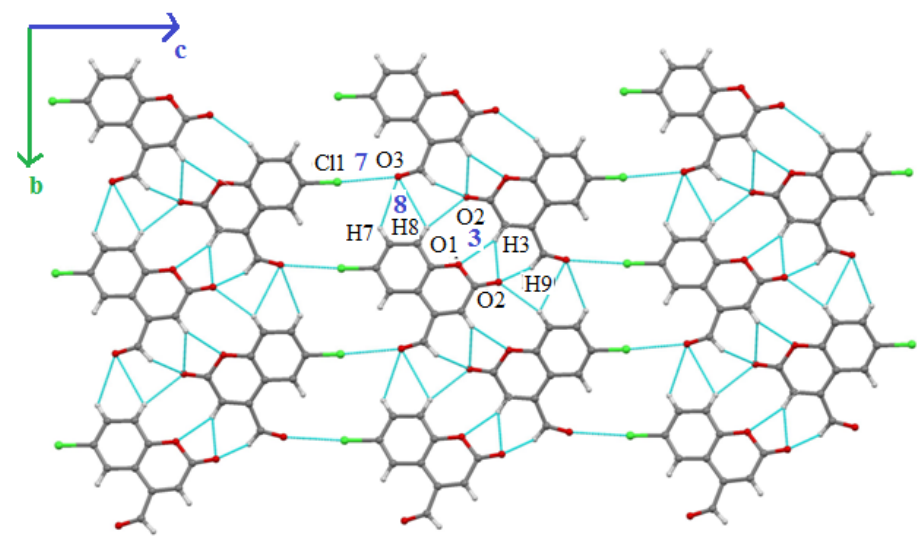

(b)

Figure 5. Packing of the molecules in C-2 showing (a) stacking of the down the ab plane (b) molecular chains interconnected via $\mathrm{Cl}$.... $\mathrm{O}$ interaction

\section{7-Chloro-4-formylcoumarin (M-3)}

The principal stabilizing molecular pairs (1-8) imparting maximum stabilization to the crystal are presented in Figure 6. The packing of the molecules in M-3 involves the stacking of the molecules along crystallographic a axis via pairs 1 and 2, contributing -7.45 and $-6.16 \mathrm{kcal}$ $\mathrm{mol}^{-1}$ respectively towards stabilization. Molecular stacks so formed are then interlinked via dimeric bifurcated C-H...O hydrogen bonds exhibited by motifs 3 and 5, forming layers in the ab plane as shown in Figure 7. Motif 3 (I.E. $=-5.32 \mathrm{kcal} \mathrm{mol}^{-1}$ ) involves the interaction of bifurcated donor atom $\mathrm{H} 8$ with $\mathrm{O} 1$ and $\mathrm{O} 2$ whereas motif 5 involves the interaction of $\mathrm{H} 5$ and H6 with bifurcated acceptor atom O3. Motif 4 involves carbonyl carbonyl interaction $(\mathrm{C}=\mathrm{O} \ldots \mathrm{C}=\mathrm{O})$ and makes a contribution of $-4.97 \mathrm{kcal} \mathrm{mol}^{-1}$ towards the stabilization, with the maximum contribution coming from dispersion energy (60\%). Motif 6 contributing -3.37 $\mathrm{kcal} \mathrm{mol}^{-1}$, shows the presence of weak C-H...O hydrogen bond involving H3 with $\mathrm{O} 2$. Motif 7 and 8 , both showing the presence of hydrogen bonds with halogens, were also found to make almost equal contributions of -1.57 and $-1.24 \mathrm{kcal} \mathrm{mol}^{-1}$ respectively towards crystal stability. Dispersion energy makes maximum contribution towards the stabilization of these motifs (Table 4), thereby indicating the dispersive nature of the halogen bonded interactions.
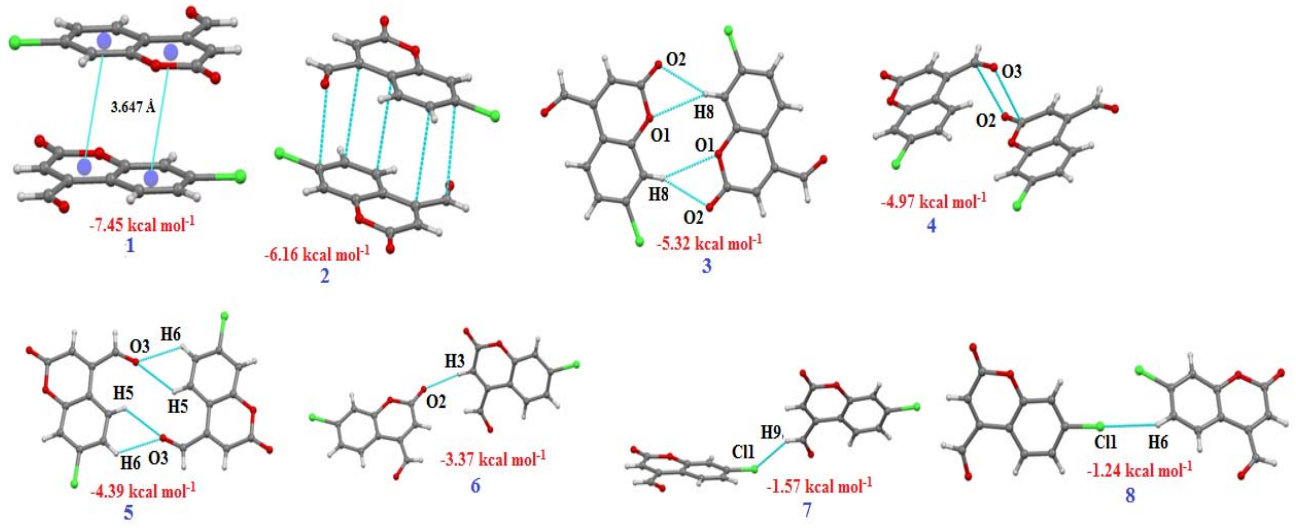

Figure 6. Molecular pairs (1-8) along with their interaction energies in C-3 


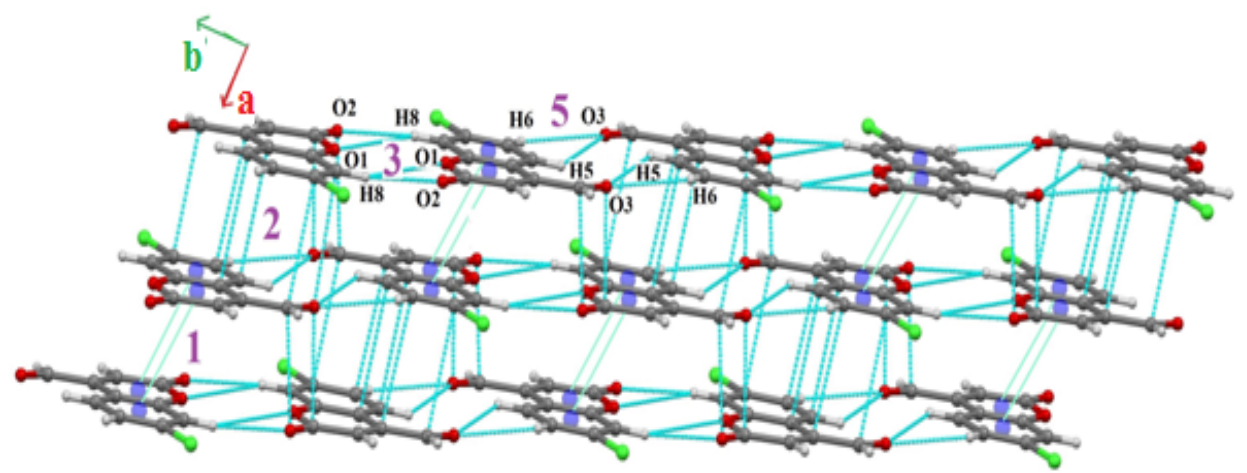

Figure 7. Packing of the molecules in C-3 down the ab plane

\section{7-Bromo-4-formylcoumarin (M-4)}

The principal stabilizing molecular pairs (1-6) extracted from the crystal packing after PIXEL calculation are shown in Figure 8 along with their respective stabilizing energies. The crystal structure involves the formation of molecular chains along the crystallographic c- axis, utilizing motif 1 and motif 5. Motif 1 having the highest energy stabilization of $6.59 \mathrm{kcal} \mathrm{mol}^{-1}(50 \%$ contribution from coulombic component), shows the presence of $\mathrm{C}\left(\mathrm{sp}^{2}\right)-\mathrm{H}$...O hydrogen bonds, whereas another $\mathrm{C}\left(\mathrm{sp}^{2}\right)-\mathrm{H} 6 . . \mathrm{O} 3$ hydrogen bond along with $\mathrm{C}\left(\mathrm{sp}^{2}\right)-\mathrm{H} 5 \ldots \mathrm{Br} 1$ binds the molecules in motif $5\left(-3.06 \mathrm{kcal} \mathrm{mol}^{-1}\right)$. The molecular chains so formed, are then stacked along a-axis via motif $2\left(-6.21 \mathrm{kcal} \mathrm{mol}^{-1}\right), 3\left(-6.07 \mathrm{kcal} \mathrm{mol}^{-1}\right)$ and $4\left(-4.71 \mathrm{kcal} \mathrm{mol}^{-1}\right)$, forming layers down the ac plane as shown in Figure 9a. Motif 4 involving $\mathrm{C}=\mathrm{O} \ldots \mathrm{C}=\mathrm{O}$ interaction is similar to motif 4 of $\mathrm{M}-3$, energy contributons are also almost same $\left(-4.97\right.$ and $\left.-4.71 \mathrm{kcal} \mathrm{mol}^{-1}\right)$. The packing in the crystal also displays the formation of zig-zag chains along b-axis via motif 1 and $6\left(\mathrm{C}=\mathrm{O} \ldots \mathrm{Br}-\mathrm{C}\left(\mathrm{sp}^{2}\right),-1.07 \mathrm{kcal} \mathrm{mol}^{-1}\right)$. The zig-zag chains are then interconnected via motif $5\left(-3.06 \mathrm{kcal} \mathrm{mol}^{-1}\right)$ generating molecular sheets in the bc plane (Figure 9b).
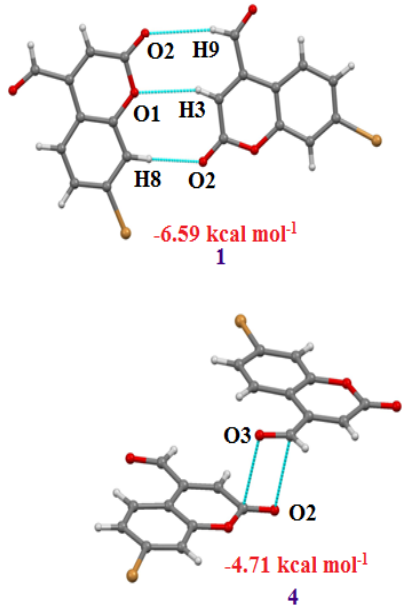

4

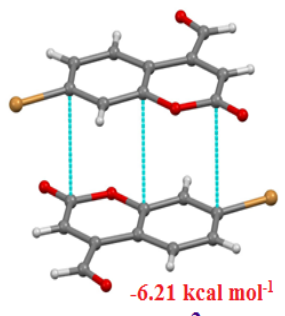

2

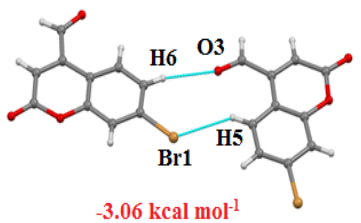

5
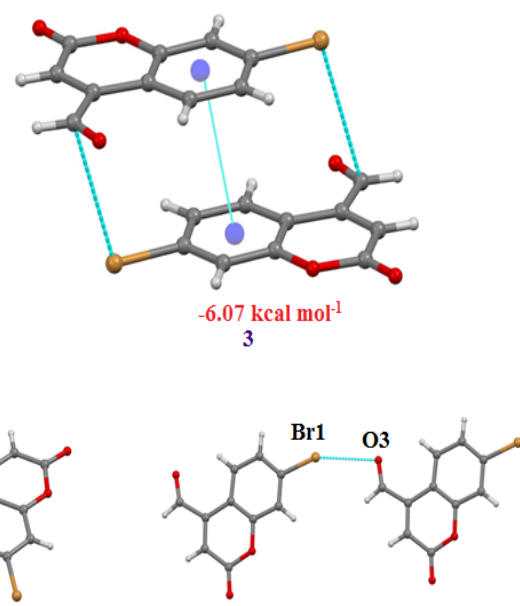

$-1.07 \mathrm{kcal} \mathrm{mol}^{-1}$

Figure 8. Molecular pairs (1-6) along with their interaction energies in C-4 


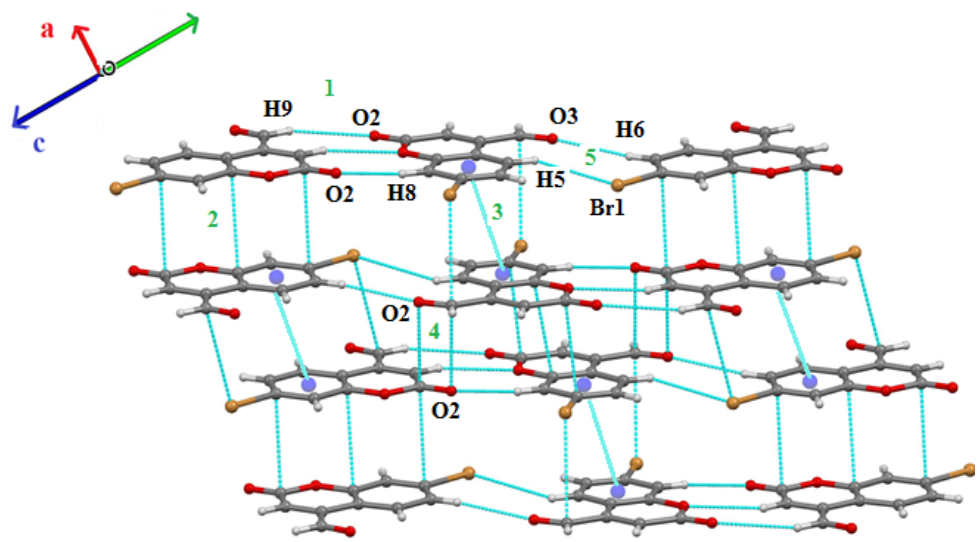

(a)

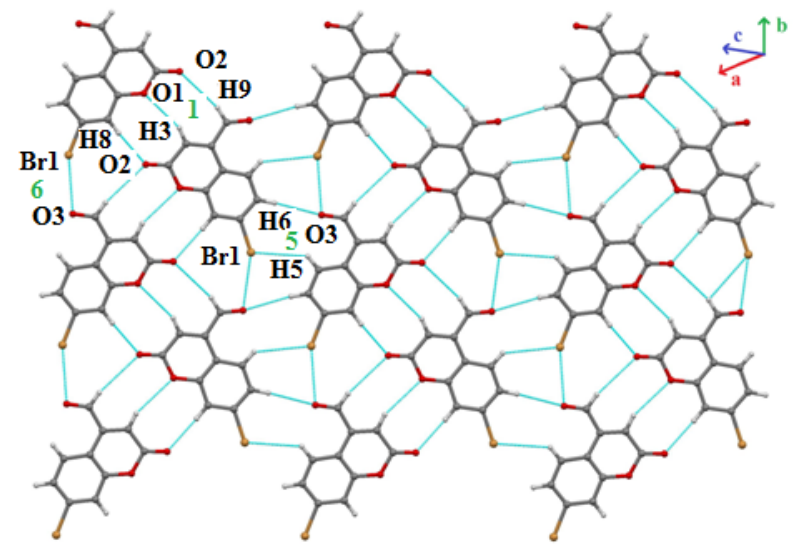

(b)

Figure 9. Packing of the molecules in C-4 showing (a) stacking of the molecules along a-axis (b) zig- zag chains formed by $\mathrm{C}-\mathrm{H}$..... O hydrogen bonds

\section{6-Fluoro-4-formylcoumarin (M-5)}

The important structural motifs (1-8) having significant energy contribution towards stabilization are shown in Figure 10 along with their stabilization energies. The maximum stabilization to the structure comes from weak but directional $\mathrm{C}-\mathrm{H} \ldots \mathrm{O}=\mathrm{C}$ hydrogen bond involving $\mathrm{H} 8$ with $\mathrm{O} 2$ (motif 1, Figure 10), forming dimers across the centre of symmetry with an interaction energy of $-6.09 \mathrm{kcal} \mathrm{mol}^{-1}$ (with $54 \%$ coulombic component). These dimers are then connected via weak dimeric C-H...F hydrogen bonds involving H5 with F1 (motif 8, I.E $=-1.5 \mathrm{kcal} \mathrm{mol}^{-1}$ ) forming chains along a axis. The chains so formed are interlinked via stacking interactions (motif 3 and 4, both having similar interaction energies of -3.89 and $-3.82 \mathrm{kcal} \mathrm{mol}^{-1}$ resp., with maximum dispersion contribution) along with $\mathrm{C}=\mathrm{O} \ldots \mathrm{C}=\mathrm{O}$ interaction (motif 2, identical to motif 4 of $\mathrm{M}-3$ and $\mathrm{M}-4$ ) having stabilization energy of $-4.97 \mathrm{kcal} \mathrm{mol}^{-1}$ (Figure 11a). The packing in the crystal also involves the formation of molecular chains via $\mathrm{C}\left(\mathrm{sp}^{2}\right)-\mathrm{H} 3 \ldots \mathrm{F} 1$ (motif 6), contributing $-2.74 \mathrm{kcal} \mathrm{mol}^{-1}$ (with significant coulombic and dispersion component) towards stabilization of the crystal structure. The molecular chains are then interconnected with more stabilized motif 2 (I.E. $=-4.97 \mathrm{kcal} \mathrm{mol}^{-1}$ ) as shown in Figure $11 \mathrm{~b}$. 


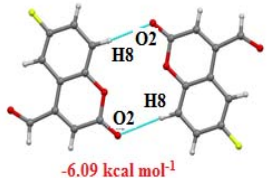

1

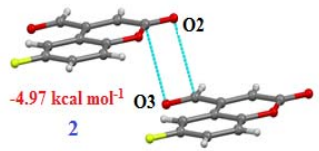

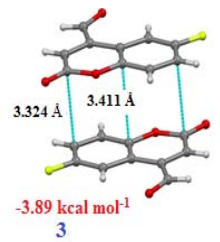

3

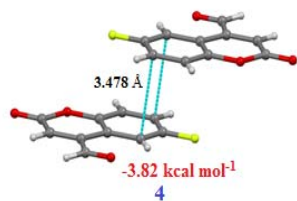

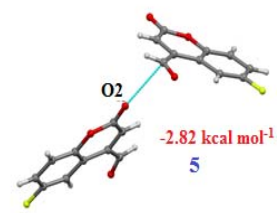
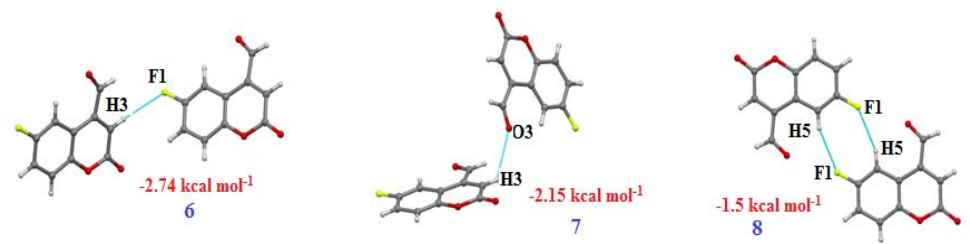

Figure 10. Molecular pairs (1-8) along with their interaction energies in C-5

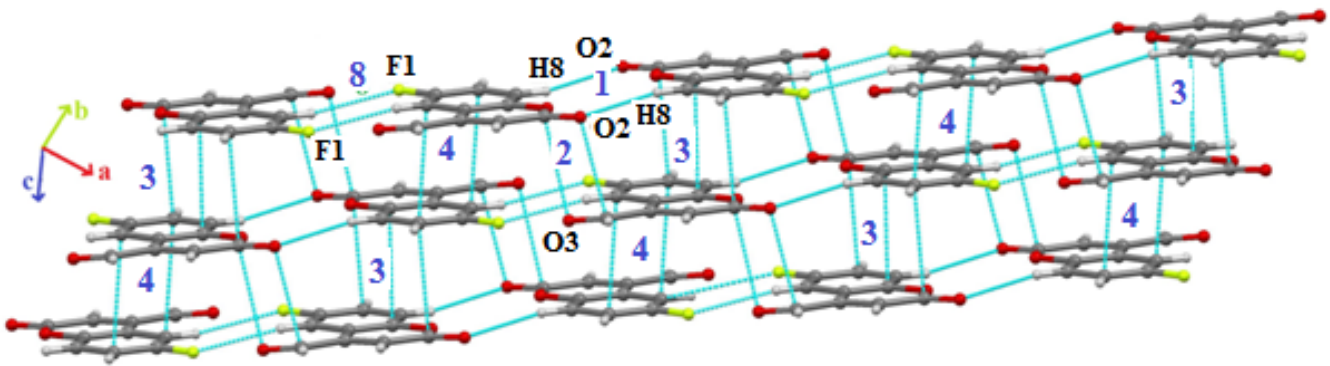

(a)

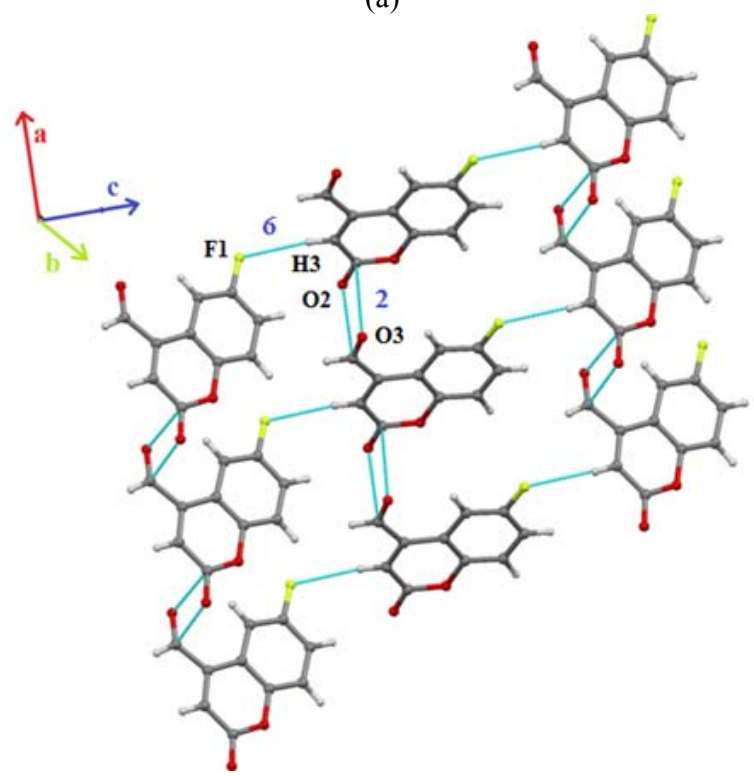

(b)

Figure 11. Packing of the molecules in C-4 depicting (a) stacking of molecules chains formed via $\mathrm{C}-\mathrm{H}$...F and $\mathrm{C}-\mathrm{H}$...O hydrogen bonds (b) formations of chains via $\mathrm{C}-\mathrm{H}$...F hydrogen bonds 


\section{7-Fluoro-4-formylcoumarin (M-6)}

Molecular pairs (1-8) imparting maximum contribution to the crystal structure are presented in Figure 12 along with their interaction energies. The packing in the crystal structure displays the formation of molecular chains along the crystallographic a-axis via dimeric $\mathrm{C}\left(\mathrm{sp}^{2}\right)-\mathrm{H} 8 \ldots \mathrm{O} 2$ hydrogen bonds as exhibited by molecular pairs $2\left(-6.33 \mathrm{kcal} \mathrm{mol}^{-1}\right.$, with mostly coulombic contribution ) and 6 involving dimeric $\mathrm{C}\left(\mathrm{sp}^{2}\right)-\mathrm{H} 5 \ldots \mathrm{O} 3\left(-4.04 \mathrm{kcal} \mathrm{mol}^{-1}\right.$, with almost equal contribution from coulombic and dispersion energies). The molecular chains so formed are then linked via motifs 1,7 and 8 (Figure 13a). Motif 1, the most stabilized pair in the structure, shows the presence of dimeric $\mathrm{C}\left(\mathrm{sp}^{2}\right)-\mathrm{H} 3 \ldots \mathrm{O} 2$ hydrogen bonds and contributes $-8.36 \mathrm{kcal} \mathrm{mol}^{-1}$ towards stabilization of the structure. Motif 7 (-2.13 $\left.\mathrm{kcal} \mathrm{mol}{ }^{-1}\right)$ involves the presence of dimeric $\mathrm{C}\left(\mathrm{sp}^{2}\right)-\mathrm{H} 6 \ldots \mathrm{F} 1$ while another $\mathrm{C} 9-\mathrm{H} 9 \ldots \mathrm{F} 1$ hydrogen bond links the molecules in motif $8\left(-0.55 \mathrm{kcal} \mathrm{mol}^{-1}\right)$. The third and fifth molecular pairs, stacked alternatively along the crystallographic b-axis, have contribution of -5.13 and $-4.52 \mathrm{kcal} \mathrm{mol}^{-1}$ to the stabilization of the crystal packing. Adjacent stacks are then connected via dimeric $\mathrm{C}\left(\mathrm{sp}^{2}\right)-\mathrm{H} 3 \ldots \mathrm{O} 2$ (motif 1) and dimeric $\mathrm{C}\left(\mathrm{sp}^{2}\right)-\mathrm{H} 6 \ldots \mathrm{F} 1$ (motif 7) intermolecular hydrogen bonds (Figure 13b).

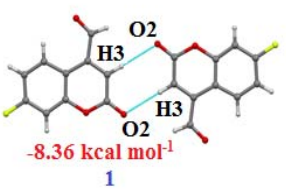

1

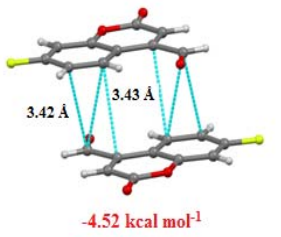

5

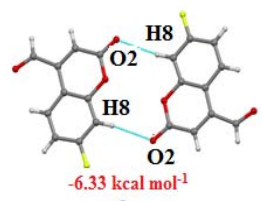

2

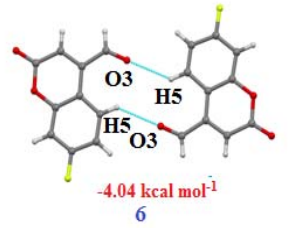

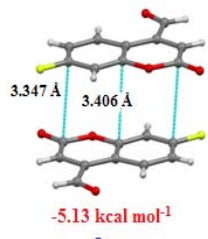

3

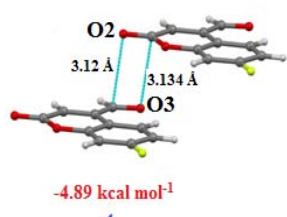

4

Figure 12. Molecular pairs (1-8) along with their interaction energies in C-6

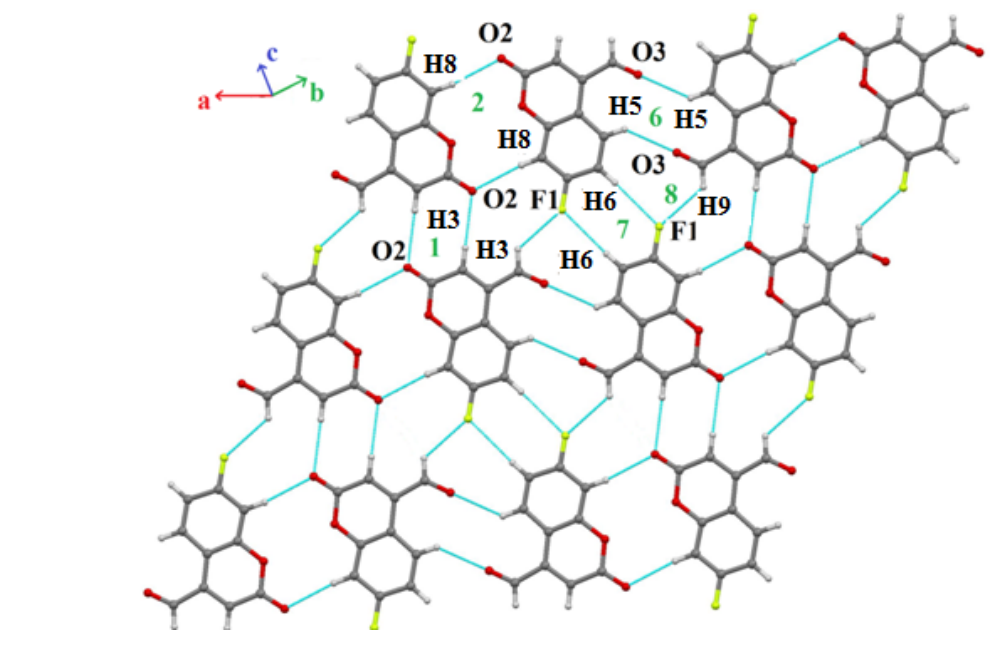

(a)
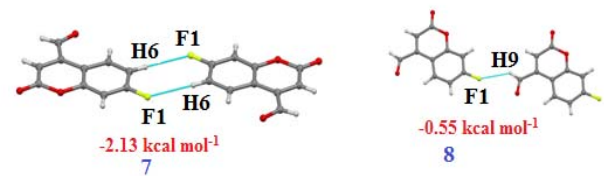

8 


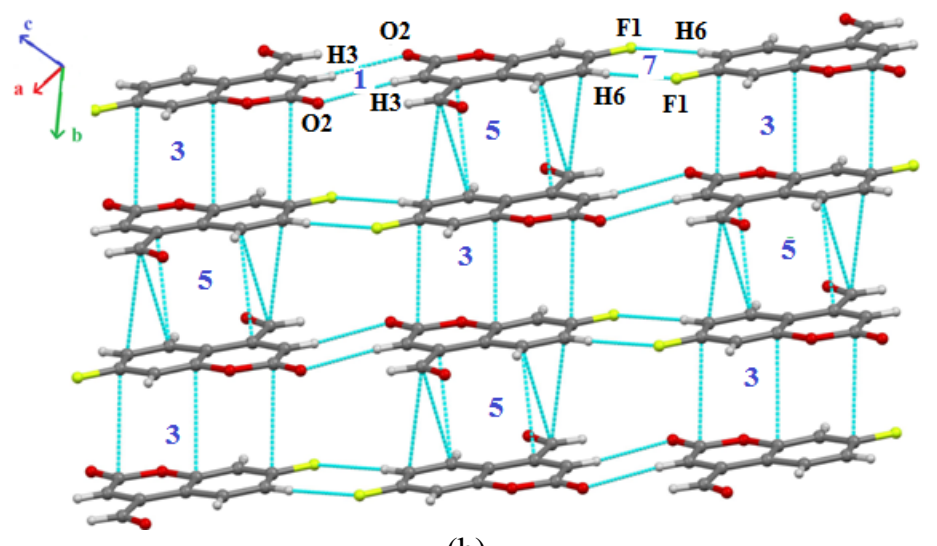

(b)

Figure 13. Packing of the molecules in C6 depicting (a) molecules chains formed via $\mathrm{C}-\mathrm{H}$...O hydrogen bonds (b) stacking of the moleciles down of the b-axis

A careful analysis of some key supramolecular motifs as obtained in these compounds leads to the following relevant observations:

1. The lattice energy of the structures lies in the range -21 to $-25 \mathrm{kcal} \mathrm{mol}^{-1}$ with maximum contribution from dispersion component.

2. The maximun stabilization to the crystal structure is imparted by molecular motifs interacting via $\mathrm{C}-\mathrm{H} \ldots \mathrm{O}$ or $\pi \ldots \pi$ stacking interaction.

3. The energy of molecular pairs interacting via $\pi \ldots \pi$ lies in the range -6 to $-7.5 \mathrm{kcal} \mathrm{mol}^{-1}$ with almost 70-90 \% contribution from dispersion component.

4. Dimeric C-H...O hydrogen bonds are also found to have significant role in the stabilization of the packing and makes an essential contribution of -3 to $-8 \mathrm{kcal} \mathrm{mol}^{-1}$ towards stabilization.

5. Motifs interacting via dimeric $\mathrm{C}=\mathrm{O} \ldots \mathrm{C}=\mathrm{O}$ interaction contributes almost $-5 \mathrm{kcal} \mathrm{mol}^{-1}$ towards stabilization and the principal stabilization of around $55-60 \%$ corresponds to dispersion component.

6. Weak intermolecular interactions involving halogen atom $\mathrm{C}-\mathrm{H} . . . \mathrm{X}(\mathrm{Cl}, \mathrm{Br}, \mathrm{F})$ is also found to make small but significant contribution towards the stabilization of the packing.

\section{Conclusion}

The present work describes the nature and energetics of weak intermolecular interactions that operate between organic molecules and cause them to condense to form ordered crystalline solids. A better understanding of these interactions operating between the atoms that help molecules to associate with each other will play an important role in the field of Crystal Structure prediction, where one tries to predict the structure of unknown crystals. PIXEL calculations enable us to distinguish several kinds of interaction that seems to play more or less important roles in the stabilization of the crystal structure.

\section{References}

1. Singh V, Singh J, Kaur P and Kad G L, J Chem Research(s), 1997, 58-59; DOI:10.1039/A807509C

2. $\quad$ Yu W, Liu Z Q and Liu Z L, J Chem Soc., Perkin Trans., 1999, 2, 969-974;

DOI:10.1039/A810022E 
3. Amin K, Abdel Rahman D E and Al-Eryani Y A, Bioorg Med Chem., 2008, 16(10), 5377-5388; DOI:10.1016/j.bmc.2008.04.021

4. Kostova I, Curr Med Chem Anti-Cancer Agents, 2005, 5, 29-46; DOI:10.2174/1568011053352550

5. Subramanian S and Zaworotko M J, Coord Chem Rev., 1994, 137, 357-401; DOI:10.1016/0010-8545(94)03008-E

6. Arunan E, Desiraju G R, Klein R A, Sadlej J, Scheiner S, Alkorta I, Clary DC, Crabtree R H, Dannenberg J J, Hobza P, Kjaergaard H G, LegonA C, Mennucci B and Nesbitt D J. Pure Appl Chem.,2011,83(8), 1637-1641; DOI:10.1351/PAC-REC10-01-02

7. Desiraju G R, Angew Chem Int Ed., 2011, 50(1), 52-59;

DOI:10.1002/anie.201002960

8. Marjo C E, Scudder M L, Craig D C and Bishop R, J Chem Soc,Perkin Trans., 1997, 2, 2099-2104; DOI:10.1039/A700494J

9. Steiner T and Desiraju G R, Chem Commun., 1998, 891-892; DOI:10.1039/A708099I

10. Nishio M, Umezawa Y, Honda K, Tsuboyama S and Suezawa H, Cryst Eng Comm., 2009, 11, 1757-1788; DOI:10.1039/B902318F

11. Nishio M, Phys Chem Chem Phys., 2011, 13, 13873-13900; DOI:10.1039/C1CP20404A

12. Takahashi O, Kohno Y and Nishio M, Chem Rev., 2010, 110(11), 6049-6076; DOI:10.1021/cr100072x

13. Dunitz J D and Gavezzotti A. Chem Soc Rev., 2009, 38, 2622-2633; DOI:10.1039/B822963P

14. Maschio L, Civalleri B, Ugliengo P and Gavezzotti A, Phys Chem A, 2011, 115(41), 11179-11186; DOI:10.1021/jp203132k

15. Kaur G, Panini P, Chopra D and Choudhury A R, Cryst Growth Des., 2012, 12(10), 5096-5110; DOI:10.1021/cg3010294

16. Vasylyrva V, Shishkin O V, Maleev A Vand Merz K, Cryst Growth Des., 2012, 12, 1032-1039; DOI:10.1021/cg201623e

17. Moorthy J N, Venkatakrishnan P and Singh A S, Cryst Eng Comm, 2003, 5(92), 507513; DOI:10.1039/B315065H

18. Gavezzotti A, J Phys Chem B, 2002, 106(16), 4145- 4154; DOI:10.1021/jp0144202

19. Gavezzotti A, $J$ Phys Chem B, 2003, 107(10), 2344-2353; DOI:10.1021/jp022288f

20. Gavezzotti A, New J Chem., 2011, 35, 1360-1368; DOI:10.1039/C0NJ00982B

21. Carlucci L and Gavezzotti A, Chem Eur J., 2005, 11(1), 271-279;

DOI:10.1002/chem.200400499

22. Dunitz J D and Gavezzotti A, Cryst Growth Des., 2012, 12(12), 5873- 5877;

DOI:10.1021/cg301293r

23. Dunitz J D and Gavezzotti A, Cryst Growth Des., 2005, 5(6), 2180-2189; DOI:10.1021/cg050098z

24. Macrae C F, Bruno I J, Chisholm J A, Edgington P R, McCabe P, Pidcock E, Rodriguez-Monge L, Taylor R, Streek J and Wood P A, J Appl Crystallogr., 2008, 41(2), 466-470; DOI:10.1107/S0021889807067908 